\title{
Preconception and Contraceptive Care for Women Living with HIV
}

\author{
Mary Jo Hoyt, ${ }^{1}$ Deborah S. Storm, ${ }^{1}$ Erika Aaron, ${ }^{2}$ and Jean Anderson ${ }^{3}$ \\ ${ }^{1}$ François-Xavier Bagnoud Center, School of Nursing, University of Medicine and Dentistry of New Jersey, 65 Bergen Street, 8th Floor \\ Newark, NJ 07101, USA \\ ${ }^{2}$ Division of Infectious Diseases and HIV Medicine, Drexel University College of Medicine, 427 Vine Street, 5th Floor, Philadelphia, \\ PA 19102, USA \\ ${ }^{3}$ Division of Gynecologic Specialties, The Johns Hopkins Medical Institutions, Phipps 247, 600 N. Wolfe Street, Baltimore, MD 21287, \\ USA
}

Correspondence should be addressed to Mary Jo Hoyt, hoyt@umdnj.edu

Received 20 February 2012; Accepted 4 June 2012

Academic Editor: Susan Cu-Uvin

Copyright ( 2012 Mary Jo Hoyt et al. This is an open access article distributed under the Creative Commons Attribution License, which permits unrestricted use, distribution, and reproduction in any medium, provided the original work is properly cited.

\begin{abstract}
Women living with HIV have fertility desires and intentions that are similar to those of uninfected women, and with advances in treatment most women can realistically plan to have and raise children to adulthood. Although HIV may have adverse effects on fertility, recent studies suggest that antiretroviral therapy may increase or restore fertility. Data indicate the increasing numbers of women living with HIV who are becoming pregnant, and that many pregnancies are unintended and contraception is underutilized, reflecting an unmet need for preconception care (PCC). In addition to the PCC appropriate for all women of reproductive age, women living with HIV require comprehensive, specialized care that addresses their unique needs. The goals of PCC for women living with HIV are to prevent unintended pregnancy, optimize maternal health prior to pregnancy, improve maternal and fetal outcomes in pregnancy, prevent perinatal HIV transmission, and prevent HIV transmission to an HIV-uninfected sexual partner when trying to conceive. This paper discusses the rationale for preconception counseling and care in the setting of HIV and reviews current literature relevant to the content and considerations in providing PCC for women living with HIV, with a primary focus on well-resourced settings.
\end{abstract}

\section{Introduction}

Access to preconception care (PCC) aimed at promoting pregnancy planning, reducing unintended pregnancies, optimizing maternal health prior to pregnancy, and using safer conception strategies is needed to optimize health outcomes for HIV-infected women and their infants, reduce adverse pregnancy outcomes, and strengthen prevention efforts for at-risk partners and children. Benefits of PCC in identifying and modifying risks to maternal health and pregnancy outcomes and in preventing unwanted pregnancies are well documented [1-3]. The American College of Obstetricians and Gynecologists (ACOG) and the Panel on Treatment of HIV-Infected Pregnant Women and Prevention of Perinatal Transmission in the United States and other national organizations recommend offering all HIV-infected women of childbearing age comprehensive family planning and the opportunity to receive preconception counseling and care as a component of routine primary medical care $[2,4]$. This paper will discuss the rationale for preconception counseling and care in the setting of HIV and review current literature relevant to the content and considerations in providing PCC for women living with HIV, with a primary focus on wellresourced settings and on elements of PCC that are specific to women living with HIV.

\section{Rationale for Preconception Care}

2.1. Advances in HIV Care and Prevention of Perinatal HIV Transmission. HIV has become a chronic disease in developed countries. A recent report from the national observational HIV cohort in the Netherlands suggested that the life expectancy of recently diagnosed, asymptomatic HIVpositive patients approaches that of uninfected individuals, 
TABLE 1: Factors associated with fertility desires and intentions in women living with HIV.

\begin{tabular}{ll}
\hline Positive influences & Negative influences \\
\hline Younger age & $\begin{array}{l}\text { Already having one or more children } \\
\text { No children }\end{array}$ \\
Antiretroviral therapy & $\begin{array}{l}\text { Concerns about infecting partner } \\
\text { Interventions for PMTCT }\end{array}$ \\
$\begin{array}{l}\text { Concerns about infecting child } \\
\text { Partner's/family members' } \\
\text { wish for children }\end{array}$ & $\begin{array}{l}\text { Negative or judgmental attitudes } \\
\text { of heare workers, family, and } \\
\text { community }\end{array}$ \\
HIV-related stigma & HIV-related stigma \\
\hline
\end{tabular}

particularly if they do not engage in high risk behaviors (e.g., injection drug use) and initiate effective antiretroviral (ARV) therapy before there is significant immune suppression [5]. With appropriate treatment, women with HIV can live normal or near normal life spans, have improved quality of life, and can realistically plan to have and raise children to adulthood. Current interventions for the prevention of mother-to-child transmission of HIV (PMTCT) have decreased perinatal transmission rates to $1-2 \%$ or less [4, 6], and it is estimated that fewer than 200 infants are infected annually in the US [7]. The majority of HIV-infected children now live to become adults $[7,8]$ and many are having children themselves $[9,10]$.

There is evidence that these or other factors are indeed resulting in an increase in births to women living with HIV. A Women's Interagency HIV Study (WIHS) cohort analysis found a $150 \%$ increase in live birth rates in the era of highly effective ARV therapy (HAART) (2001-2002) among HIV-infected women when compared to the pre-HAART era (1994-1995); during the latter time period, there was only a $5 \%$ increase in live birth rates among HIV-uninfected women in WIHS [11]. Increases were seen in all age and CD4 categories, with the greatest increase (306\%) among women older than 35 years. Another WIHS analysis suggested that abortion was significantly less likely in the HAART era [12].

2.2. Fertility Desires and Intentions. Studies of fertility desires and intentions have shown that many women living with HIV want to have children [13-16]. In a recent survey of 450 HIV-infected women in the United Kingdom, 75\% reported that they wanted more children, $11 \%$ stated that the HIV diagnosis made them want children sooner, and $41 \%$ of women who initially reported no desire to have children changed their minds following advances in HIV care [14]. As shown in Table 1, factors that have been associated with fertility desires and intentions [17-19] reflect issues related to personal health, ARV therapy, HIV transmission, and social factors [13-16, 18]. Findings from the recent Women Living Positive survey illustrate the perceived dichotomy between personal and societal perspectives on childbearing among women with HIV [19]. Although a majority (61\%) of the 700 respondents believed that with appropriate medical care they could safely have children, $59 \%$ believed that society strongly urges them not to have children. An exploratory survey/interview with $74 \mathrm{HIV}$-positive women found that those with higher levels of personalized stigma and negative self-image reported increased desire for children as a way of concealing their HIV-positive status and improving feelings of self-worth [17]. However, some women who had disclosed their HIV status reported they were less likely to become pregnant in order to avoid negative judgments about the risk of transmitting HIV to their child [17, 19]. A recent comparison of childbearing desires and motivations between HIV-infected and HIV-uninfected urban, largely AfricanAmerican youth (15-24 years old) found that HIV infection had no effect on desire for pregnancy [20].

2.3. High Rates of Unintended Pregnancy. The most recent US data indicates that nearly half $(49 \%)$ of pregnancies are unintended, with unintended pregnancy rates among women who were 18-24 years old, poor or cohabitating were two to three times the national rate [21]. Studies among women living with HIV suggest that unintended pregnancies among HIV-infected women are equally high or higher and may be influenced by similar cultural and societal factors [12, $17,19]$. Unintended pregnancy rates of $54 \%$ were reported in Canadian women after HIV diagnosis [16] and 62\% among HIV-infected women after ART initiation in both South Africa and Rwanda [22]. Unintended pregnancy is even more prevalent among adolescents with HIV, $83 \%$ in a cohort of US adolescents [23] and 81\% in adolescents in the UK and Ireland growing up with HIV [24].

In the WIHS cohort analysis of pregnancies between 1994 and 2002, 77\% of pregnancies occurred despite use of contraception [12], implying that the pregnancies were unintended and highlighting the importance of adequate and accurate counseling about use of effective birth control. Across almost 27,000 visits by 2784 HIV-infected and highrisk HIV-uninfected women in the WIHS cohort from 1994 to 2005 , barrier methods were used in $<40 \%$ of visits, hormonal methods in fewer than $10 \%$, and no contraception in over $30 \%$ of visits [25]. HIV status was not correlated with barrier use but hormonal contraception was less likely among women with HIV (OR 0.73 , 95\% CI 0.60-0.89, $P=0.002)$. These data provide evidence of the underuse of hormonal contraception and barrier methods that leaves women with HIV at risk for unintended pregnancy, HIV transmission and acquisition of other sexually transmitted infections (STIs).

\subsection{Unmet Need for Discussions about Pregnancy. Women} living with HIV express the desire to talk about reproductive plans with their healthcare providers; however, data suggest that such counseling does not often occur until after conception $[19,26,27]$. In a recent study of 181 women, $67 \%$ reported having a general discussion about pregnancy with their HIV health provider, but only $31 \%$ of women reported a discussion that was personalized and specific to their future childbearing plans. Of those who had a personalized discussion, most were initiated by the patient rather than the provider [26]. The Women Living Positive survey found that only $42 \%$ of women who were currently or previously 
TABLE 2: Components of preconception counseling for women living with HIV.

Current and future desires and plans to have children by woman, her partner and family and desired timing of pregnancy

Contraceptive options (for women who do not wish to become pregnant or who wish to delay pregnancy for better birth spacing or while health or nonhealth-related issues are managed)

Effect of HIV and ARVs on pregnancy course and outcomes

Effect of non-HIV-related factors on pregnancy and pregnancy outcome: for example, age, drug use, other medical conditions

Optimization of maternal health status and timing of pregnancy

Counseling on safer sexual practices and other counseling on healthy living (smoking cessation, eliminating alcohol, treatment for illicit drug use)

Options for conception that decrease risk of HIV transmission to an HIV-uninfected partner

Perinatal HIV transmission and PMTCT: the role of ARVs for mother and baby, mode of delivery, avoidance of breastfeeding, infant ARV prophylaxis

Long-term care plans, including advance directives and care of children if one or both parents were to become ill or die

pregnant had discussed pregnancy and appropriate HIVrelated care before becoming pregnant [19]. Findings also indicated that many women had little or no awareness of the available treatment options for pregnant women with HIV.

2.5. HIV Serodiscordance in Couples. Although recent data are not available, a study of a population-based sample of HIV-infected persons in care in 1996 found that $58 \%$ of men and $70 \%$ of women had a primary partner or spouse; approximately $50 \%$ of couples were in serodiscordant relationships and almost 20\% were in relationships with partners whose HIV status was unknown [13]. Extrapolating from this information and incorporating 2006 data about number and demographics of heterosexual adults living with HIV in the U.S., it has been estimated there are approximately 140,000 HIV-heterosexual serodiscordant couples in the US, about half of whom want more children [28]. This has significant implications about the need to provide accurate information about achieving safe conception in the presence of HIV discordance.

2.6. Potential Improvement in Fertility with ARV Therapy. A number of studies have suggested that HIV has an adverse effect on fertility in both symptomatic and asymptomatic women [29-33]. This includes both a decrease in pregnancy rates and an increased risk of pregnancy loss. The reason for this association is not entirely clear; it may be multifactorial and both directly and indirectly related to HIV. Although women with HIV have similar prevalence of gonorrhea and chlamydia infections as compared to high-risk HIVuninfected women $[34,35]$, the majority of HIV-infected women are exposed to HIV sexually and history of other sexually transmitted infections is common, including infections that have an adverse effect on fertility. Sexually transmitted organisms, including N. gonorrhea and C. trachomatis, are implicated in most cases of pelvic inflammatory disease (PID), a major cause of infertility due to tubal damage. Furthermore, the clinical presentation among HIV-infected women with PID may be more severe than in uninfected women [36, 37]. A cross-sectional study from Spain of 130 HIV-infected women undergoing fertility assessment found that almost one-third had evidence of tubal occlusion [38]. Another potential contributing factor to subfertility in HIV-infected women is a possible increase in amenorrhea, oligomenorrhea, and irregular periods, particularly with lower CD4 counts [39-42]. Higher viral loads have also been independently associated with decreased fertility [33].

Recent data suggest that effective ARV therapy may restore or improve fertility $[43,44]$. In an analysis from Rakai, Uganda, the pregnancy incidence almost doubled in women on ART as compared to women in pre-ART care; pregnancy rates were highest among women with good immunologic response to ART [43]. In a retrospective cohort study from Malawi, women on ART for at least 6 months had similar total fertility rates to women in the general; in multivariable analysis, longer time on ART was associated with increased probability of becoming pregnant [45]. Therefore, as women receive effective treatment, they may become at increased risk for unintended pregnancy.

\section{Counseling and Assessment on Childbearing and Contraception}

The components of preconception counseling for women living with HIV are summarized in Table 2. Because the decision to have a child is complex and may change over time, childbearing desires and intentions should be assessed during the initial evaluation and at intervals throughout the course of care. Formal preconception counseling, including contraceptive discussions, should take place when (1). The woman expresses a desire for future pregnancy or (2). She is uncertain about her plans or (3). She is not trying to conceive but is not using effective and consistent contraception.

Women's reproductive decisions are shaped by numerous personal, interpersonal, health-related, and socioeconomic factors which may make them reluctant to initiate discussions with healthcare providers [18]. Therefore, clinicians should be proactive in initiating discussions about childbearing, contraception, and reproductive health. Potential barriers to preconception counseling and care, described in Table 3, must be recognized and addressed in order to appropriately meet the reproductive health needs of HIV-infected 
TABLE 3: Potential barriers to preconception counseling and care for women living with HIV.

\begin{abstract}
Limited visit time
Competing priorities and more immediate concerns related to care of HIV and comorbidities

Reluctance of clinicians and HIV-infected women to discuss reproduction/fertility

Assumptions that HIV-positive women donnot want to become pregnant

Effects of the stigma associated with HIV

Challenges associated with lack of empowerment or control in sexual matters among HIV-infected women

Lack of knowledge about contraceptive counseling and PCC among HIV care providers

Lack of knowledge about HIV-specific elements of PCC and counseling among obstetricians and gynecologists (OB/GYNs)

Lack of clearly defined roles for multiple clinicians, for example, HIV provider, OB/GYN, primary care provider
\end{abstract}

TABLE 4: Components of the preconception evaluation for women living with HIV.

(1) History

(a) Comprehensive HIV history: when diagnosed; history of OIs or other HIV-related illnesses; ARV history (including use in prior pregnancies); reason for change in ARV regimens (adverse effects, resistance, tolerability); adherence history/challenges; results of resistance tests; nadir and current CD4 count; current HIV-RNA level

(b) Obstetric/Gynecological (OB/GYN) history

(i) Pregnancy history: number of previous pregnancies and their outcomes: miscarriages, abortions, ectopic pregnancy, preterm births; number of living children and ages; number of HIV-infected children; pregnancy complications (preterm labor, preeclampsia, birth defects, and so forth); mode of deliveries

(ii) GYN history: prior and current contraception use and satisfaction with method, adverse effects; current condom use; history of sexually transmitted/genital tract infections; difficulty getting pregnant in past; abnormal pap smears and treatment;

other GYN problems and treatment (e.g., fibroids, endometriosis, etc.)

(c) General medical/surgical history: other medical conditions (e.g., diabetes, hypertension, renal or cardiac disease, depression or other psychiatric illness, etc.); all prior surgeries; blood type and history of transfusions; allergies

(d) Immunization history: HBV, HAV, influenza, pneumococcus, HPV, tetanus

(e) Medications: complete list, including over-the-counter or complementary medications

(f) Nutrition assessment: vegetarian or other special diet, use of nutritional supplements/vitamins, history of anemia or nutritional deficiencies

(g) Social history: relationship status; use of illicit drugs/tobacco/alcohol; employment status; social support and disclosure to partner/others; economic support; history of domestic violence and nature of violence (physical, sexual, psychological)

(h) Family history of heritable diseases: birth defects, chromosomal abnormalities, muscular dystrophy, sickle cell disease, mental retardation, etc.

(i) Relevant male partner history: HIV status and knowledge of partner's status; if HIV-infected: disclosure history; history of OIs, other HIV-related conditions; ART history and history of adverse effects, resistance, adherence problems; nadir/current CD4 count; current HIV-RNA level; medical/reproductive history; medications; use of illicit drugs, tobacco, alcohol; employment

(2) Examination: comprehensive, with focus on genital tract

(3) Laboratory: emphasis on labs that will affect counseling and/or result in changes in care prior to pregnancy

(a) STI screening (gonorrhea/chlamydia; syphilis; HSV culture or HSV-2 antibody (if indicated by exam or history in patient or partner)

(b) $\mathrm{CBC}$

(c) Current CD4/HIV-RNA, resistance testing (if indicated)

(d) Rubella

(e) Hepatitis: HBV: HBsAb (if no history of HBV vaccination), HBsAg; HCV antibody, HCV-RNA, if indicated

(f) Pap

(g) Other as indicated by medical history, medications

women [26, 46-48]. A newly released clinician toolkit about PCC for women living with HIV, developed with input from a stakeholder group of clinical experts and clients, offers a resource aimed at reducing some of these barriers http:// www.fxbcenter.org/resources_clinical.html\#clinician.
Conducting a comprehensive evaluation, as outlined in Table 4, provides information to tailor preconception interventions to meet each woman's needs. Whenever possible both partners should be involved in preconception discussions [49]. 


\section{Interventions for Women Wishing to Conceive}

4.1. Support for Disclosure of Diagnosis. Supporting women's abilities to disclose their HIV diagnosis to sexual partners is an integral part of PCC and has important implications for women's health, HIV prevention and safer conception. Although few studies have focused on disclosure among women in well-resourced settings, disclosure of HIV-positive status by women to their sexual partners has been reported at $70-75 \%[50,51]$. Lack of disclosure has been associated with nonadherence to ARV therapy [52] and with nonoptimal PMTCT interventions including late initiation of ARV therapy, detectable HIV-RNA level at delivery, and lack of neonatal prophylaxis [53]. Referrals to psychosocial care providers and HIV focused community-based agencies can be helpful in supporting women through the disclosure process [54]. The primary provider's relationship with the patient can also support disclosure; however, it is also critical that reasons for nondisclosure be considered and addressed, such as fears of abandonment or violence [54-56].

4.2. Optimization of General Medical Conditions. Overall health should be optimized and health care coordinated with other providers to ensure attention to standard primary care and management of chronic diseases. A number of chronic medical illnesses (e.g., hypertension, diabetes, depression, seizure disorders) occur not infrequently in individuals with HIV and certain conditions may be associated with HIV or its treatment. Many of these illnesses are associated with adverse maternal and/or fetal outcomes, and medications used to treat them may also be associated with potential harm. Furthermore, ARV agents are associated with increased risk of certain chronic problems, such as glucose metabolic abnormalities [57, 58].

All current medications, including prescription, overthe-counter and complementary medications, should be reviewed and potential adverse effects associated with the drugs assessed. FDA drug classification can give some guidance about what is known or not known about potential teratogenic risk with use during pregnancy, based on animal data and human experience. A drug classified as FDA category D indicates positive evidence of human fetal risk, but potential benefits to mother may make risk acceptable; FDA category $\mathrm{X}$ indicates evidence of human fetal risk, which clearly outweighs any possible benefit. If a woman is taking an FDA category D or X drug, then the feasibility of safely stopping or substituting a drug that may be safer in pregnancy should be determined. For many drugs, in particular newer medications, experience in human pregnancy may be extremely limited and decisions should be made on a case by case basis, based on individual medical needs and the availability of alternative medications with equal efficacy and better safety profile. In general, teratogenic risk is limited to the first trimester of pregnancy when major fetal structures form, but often before pregnancy is realized. It is also important to remember that there can be other potential adverse effects of medications on the mother, fetus or pregnancy course which should be considered as well when a woman is planning to conceive.

Women should be evaluated for the need for appropriate prophylaxis or treatment for opportunistic infections (OIs) before attempting to conceive. Medications for OI treatment or prophylaxis should be carefully chosen based on safety, tolerability, and potential toxicity considerations when used in pregnancy [4]. Assessment prior to conception also allows the provider to implement appropriate management of anemia or other nutritional deficiencies.

4.3. Initiation or Modification of $A R V$ Regimen. An assessment of the need to initiate or modify an ARV regimen should be made for all women living with HIV prior to conception. ARV therapy should be initiated in women who meet the criteria for HIV treatment according to the Department of Health and Human Services (DHHS) Guidelines for the Use of Antiretroviral Agents in HIV-1Infected Adults and Adolescents [52] and should be strongly considered when the male partner is not HIV-infected prior to attempting to conceive, with the primary treatment goal of achieving a stable, maximally suppressed maternal viral load prior to conception [4]. The choice of ART regimen should take into account current adult treatment guidelines, what is known about the use of specific drugs in pregnancy and the risk of teratogenicity or other adverse effects. Even in women with high CD4 cell counts and in seroconcordant relationships, initiation of ARV therapy prior to conception may still be considered; early and sustained control of HIV viral replication potentially reduces the risk of perinatal transmission $[59,60]$. However, the potential adverse effects of ARV therapy on certain pregnancy outcomes, readiness for life-long therapy, and risks versus benefits of stopping ARV therapy postpartum should be part of the deliberations [61, 62]. If a current ARV regimen is not effective (i.e., suboptimal suppression of viral load), not well tolerated, or associated with significant adverse effects, then it should be modified prior to attempts at conception. Efavirenz (EFV) is the only ARV drug with evidence of teratogenic risk, based on preclinical primate data and retrospective case reports after first trimester human exposure; however, recent data suggest that the risk is likely to be quite low [63]. Nevertheless, in women who are initiating ART prior to attempts to conceive, EFV should be avoided, if possible. For women planning to conceive and already on an effective ART regimen including $\mathrm{EFV}$, regimen modification should be considered if there are available, acceptable, and effective alternatives.

4.4. Screening for Genital Tract Infections. Both partners should be screened for genital tract infections and treated if present. Genital tract inflammation is associated with genital tract shedding of HIV, even in the setting of fully suppressed HIV viral load, and may additionally increase plasma viremia $[64,65]$. If untreated, genital tract infections may increase the risk of adverse pregnancy outcomes and potential perinatal transmission. Syphilis, HSV, and vaginal infections (bacterial vaginosis, yeast, trichomoniasis) have all been associated with increased risk of perinatal transmission 
[66-68]. Couples should be counseled on safer sexual practices that prevent secondary HIV transmission to sexual partners, protect women from acquiring STIs, and reduce the potential to acquire more virulent or resistant strains of HIV $[4]$.

4.5. Treatment of Drug and Alcohol Abuse and Assistance with Smoking Cessation. It is important to address modifiable factors that contribute to the risks of adverse pregnancy outcomes for all women and pose additional risks for women with HIV. About $40 \%$ of persons with HIV are current smokers [69] in contrast to 19\% of adults in the US [70]. Among persons with HIV who are in care, data indicate that about half drink alcohol [71, 72], and while statistics vary, studies indicate that alcohol abuse or dependence is a common problem [73]. Alcohol consumption has been linked to increased HIV disease progression and reduced adherence to antiretroviral therapy $[73,74]$. Although the majority of women become HIV-infected through sexual contact, $12 \%$ of Black African/American and Latino women and $25 \%$ of white women acquire HIV through injection drug use [75]. Studies have shown that alcohol and drug use are associated with risky sexual behaviors [76-78] that can contribute to acquisition of STIs or transmission of HIV. A study using the Enhanced Perinatal Surveillance system in 15 US jurisdictions for birth years 2005 through 2008 found that women with HIV who abused substances (smoking, alcohol, or drugs) were twice as likely to have an infected infant compared to women who did not [79].

Tobacco, alcohol, and drug abuse are all associated with poor maternal health but are also associated with adverse pregnancy and fetal outcomes. As much as $13 \%$ of subfertility and delay in time to conception in the general population has been attributed to smoking [80] and smoking has also been associated with pregnancy complications, including low birth weight (LBW) and pregnancy loss [81, 82]. In an analysis of hospital discharge records linked to birth records from the state of Florida for 1998-2007, Aliyu et al. [83] found that cigarette use and maternal HIV status were independent predictors of LBW, preterm birth, and small for gestational age (SGA), with the greatest risks, approximately a two-fold increase, among mothers who were HIV positive and smoked during pregnancy.

Opiate-dependent pregnant women have a significant increase in obstetrical and neonatal complications, including preeclampsia, low birth weight, neonatal withdrawal, neurobehavioral deficits, and increased perinatal mortality [84]. Cocaine use in pregnancy significantly increases risk of preterm birth, low birth weight, miscarriage, and placental abruption [85]. Alcohol appears to have negative effects throughout pregnancy and is associated with stillbirth and fetal alcohol syndrome, as well as more subtle difficulties with learning [86]. Identifying and addressing both legal and illicit substances of abuse is critical to deal with prior to conception whenever possible.

4.6. General Management Considerations. As with all women planning pregnancy, immunizations should be given, as indicated, and folic acid supplementation should be started. Many of the same behaviors that put women at risk of acquiring HIV also put them at risk for HBV infection and HIV infection is associated with increased risk of developing chronic HBV infection [87], more rapid progression of HBVrelated liver disease, hepatocellular carcinoma (HCC), and fatal hepatic failure $[88,89]$. Therefore, $\mathrm{HBV}$ vaccine is recommended for all susceptible HIV-infected individuals. Folic acid supplementation has been associated with reduced risk of neural tube defects, although it is unknown whether this benefit applies to women who conceive on EFV.

Women living with HIV who are unable to conceive should receive fertility evaluation and management. The American Society for Reproductive Medicine (ASRM) asserts that although HIV-infected patients may be referred to providers with more expertise in providing infertility services if their provider lacks that expertise, HIV-infected patients should not be denied access to health services solely based on their HIV status and that HIV antidiscrimination laws apply both to public or private settings [90].

\section{Safer Conception with Serodiscordant Couples}

There are an estimated 140,000 HIV-heterosexual serodiscordant couples in the US, about half of whom want more children [28]. The evidence suggests that many HIVdiscordant couples have unprotected sex in their efforts to conceive [91]. Couples should be counseled regarding specific interventions to reduce the risk of transmission to an uninfected partner and approaches tailored to address specific needs, which may vary from couple to couple. It is important to confirm that the partner's HIV status is known and that the HIV status of the infected partner has been disclosed. Sensitive counseling and psychological support for disclosure and HIV testing of a partner of unknown HIV status should be coordinated with the HIV primary care team.

5.1. ARV Therapy as Prevention. Observational studies and a meta-analysis have demonstrated a decreased rate of HIV transmission among heterosexual serodiscordant couples on ARV therapy, particularly with fully suppressed HIV viral load [92]. Recent data from HPTN 052, a randomized clinical trial designed to evaluate the effectiveness of ARV therapy for prevention of sexual transmission among serodiscordant couples, found that earlier initiation of ARV therapy (at CD4+ cell counts of $350-550 / \mathrm{mm}^{3}$ ) reduced HIV transmission to the uninfected partner by $96 \%$ [93]. The recommendation, therefore, is to initiate ARV therapy in an infected partner with a CD4+ cell count $<550 / \mathrm{mm}^{3}$ to protect the uninfected partner while the couple is trying to conceive, and to consider initiation of ART if the infected partner has higher CD4+ cell counts [4]. Recently, updated guidelines for nonpregnant adults and adolescents recommend that ART be offered to all patients who are at risk for transmitting HIV to a sexual partner [52]. Maximal viral suppression is recommended before attempts at conception. 
Treatment of an infected partner does not fully protect against HIV transmission, even in the setting of maximal plasma viral load suppression. Although effective ARV therapy decreases virus in genital secretions, discordance between plasma and genital viral loads has been reported. HIV-infected males may have isolated semen HIV shedding even when plasma viral load is undetectable $[94,95]$ and independent of semen drug levels and ARV regimen [96]. Additionally, ARV genital tract penetration varies among ARV agents [97].

5.2. Female HIV Infected/Male HIV Uninfected. The uninfected partner of an HIV-infected woman should be encouraged to use condoms with each act of intercourse. Intravaginal insemination for conception using the partner's semen is effective with normal fertility and can be performed at home or by the care provider. Timed insemination during the most fertile period may be considered to maximize the chance of conception.

5.3. Male HIV Infected/Female HIV Uninfected. Male fertility screening and interventions to reduce the risk of HIV transmission during conception should be considered in this context.

5.3.1. Semen Analysis. Semen abnormalities are more common in the setting of HIV. Abnormalities are correlated with lower CD4+ cell counts and may include lower sperm volume, concentration, and motility along with higher rate of abnormal forms $[98,99]$. Some data suggest that ARV therapy may have an adverse effect on semen quality: a longitudinal study of 34 men with serial semen analyses prior to ARV therapy and up to 48 weeks post-ARV initiation found that the proportion of progressively motile spermatozoa was low at all time points, but decreased significantly over the course of followup [100]. Therefore, when there is little or no likelihood of natural conception, an uninfected female partner may be at increased risk for infection through repetitive exposure over time.

5.3.2. Preexposure Prophylaxis (PrEP). Providing ARVs intravaginally or orally to an uninfected female partner may offer additional risk reduction to minimize HIV transmission when trying to conceive. Results of PrEP clinical trials to date have been mixed. One percent intravaginal tenofovir (TDF) gel used before and after sex reduced HIV acquisition by $39 \%$ in the CAPRISA 004 study [101]. However, in the VOICE study, in women at high risk of acquiring HIV, 1\% TDF gel arm used daily was no better than placebo. A study of daily oral TDF+ emtricitabine (FTC) in uninfected male couples reported a 44\% reduction overall in HIV acquisition as compared to placebo; effectiveness was significantly affected by adherence $[102,103]$. In the Partners PrEP study conducted in Kenya and Uganda among more than 1,400 HIV serodiscordant couples, the use of daily TDF or daily TDF/FTC by the uninfected partner was found to have an efficacy of $66 \%$ and $73 \%$, respectively, compared to placebo, in reducing HIV transmission. In another trial in Botswana,
TDF/FTC given to 1,200 HIV-uninfected heterosexual men and women reduced transmission by $66 \%$ compared to placebo [104]. However, the FEM-PrEP clinical trial and the VOICE study, which were both conducted in high risk uninfected African women, found no efficacy with daily oral TDF/FTC and TDF, respectively [104]. Currently, data are insufficient to recommend PrEP as part of a strategy to reduce risk of HIV transmission when trying to conceive. If clinicians elect to use PrEP for HIV-uninfected women in serodiscordant couples, the couple should be fully educated about the potential risks and benefits and all available alternatives for safer conception.

5.4. Assisted Reproductive Technology. Assisted reproductive technology can be considered to minimize the risk of HIV transmission for serodiscordant couples. Ethics guidelines from the American College of Obstetricians and Gynecologists state that "Seropositivity for HIV per se should not be used as a reason to refuse to provide assisted reproductive technology to a family." [105].

The method with the lowest reported risk of transmission is semen washing, with negative PCR testing after preparation, coupled with intrauterine insemination (IUI), in vitro fertilization (IVF), or intracytoplasmic sperm injection (ICSI). A retrospective multicenter study at a network of eight European centers and involving 1036 serodiscordant couples used sperm washing to obtain motile spermatozoa for 3390 assisted reproduction cycles [106]. An HIV test was performed in female partners at least six months after assisted reproduction attempt. Outcome measures were the number of assisted reproduction cycles, pregnancy outcome and HIV test on women after treatment. The result of female HIV testing after assisted reproduction was known in 967 of 1036 women (7.1\% lost to followup); all tests recorded were negative. A total of 580 pregnancies were documented from 3315 cycles, resulting in 410 deliveries and 463 live births; pregnancy outcome was unknown in 47 cases. These data are suggestive but not conclusive of a safety benefit of sperm washing and assisted reproduction over natural conception. There are no data examining comparative or additional safety of these techniques in serodiscordant couples where the infected partner is on effective ART.

Some states continue to have laws that ban assisted conception with semen from HIV-infected men [107] and some clinics may limit or deny services to HIV-infected couples [90]. In addition, most insurance plans (including Medicare/Medicaid) do not cover these services and the cost is usually prohibitive. The National Perinatal HIV Hotline (1-888-448-8765) can provide a list of institutions offering reproductive services for HIV serodiscordant couples.

5.5. Timed Unprotected Intercourse. For serodiscordant couples who cannot afford assisted reproduction and who, after comprehensive counseling, still wish to try to conceive, timed unprotected intercourse with strong recommendation to use condoms at all other times is the best approach. Unprotected intercourse should be considered only in the context of viral suppression and should be targeted to those times when 
women are most likely to conceive. The most fertile time in a woman's menstrual cycle can be determined with use of ovulation predictors (available over the counter at pharmacies), basal body temperature measurement, or ovulation calculators (e.g., the March of Dimes ovulation calendar is available at http://www.marchofdimes.com/ovulation_calendar.html).

\section{Interventions for Women Wishing to Prevent or Delay Pregnancy: Contraception Management and Safety}

6.1. Contraception: General Considerations. General considerations for contraceptive counseling include those applicable to all women: efficacy, safety and side effects, convenience and ease of use, cost, potential noncontraceptive benefits, and protection against transmission of HIV or acquisition of other STIs. In addition, there are considerations specifically relevant to women with HIV, such as potential drug interactions and possible effects on HIV transmission or progression.

Women living with HIV can potentially use all available contraceptive methods [108, 109]. Current guidance from the World Health Organization (WHO) and the Centers for Disease Control and Prevention (CDC) state that with use of methods involving spermicides (alone or with diaphragm) risk generally outweighs advantages of the method, because of potential disruption of cervical mucosa, which may increase viral shedding and HIV transmission to uninfected partners. Both the copper intrauterine device (Cu-IUD) and levonorgestrel-containing IUD can be initiated or continued in women living with HIV, including those with AIDS, who are clinically doing well on ARV therapy $[110,111]$.

6.2. Drug Interactions. There are concerns that pharmacokinetic interactions between hormonal contraceptives (HCs) and ARV drugs may modify steroid levels and potentially decrease contraceptive effectiveness [112] or increase risk of adverse effects. HCs are primarily metabolized by conjugation pathways (glucuronidation and sulfonation) as well as cytochrome P450 enzymes. Specific ARV drugs, such as protease inhibitors (PIs) and nonnucleoside reverse transcriptase inhibitors (NNRTIs), can affect these metabolic pathways through induction or inhibition resulting in altered concentrations of steroid hormones. These interactions are pharmacokinetic; the true clinical effect is not clear. Therefore, additional or alternative methods of contraception are recommended in some cases. Only with fosamprenavir (FPV), which is metabolized to amprenavir (APV), does the drug-drug interaction also reduce the concentration of the $\mathrm{ARV}$; it is recommended that FPV be administered with hormonal contraceptives only when combined with low dose ritonavir (RTV) as a boosting agent. The nucleoside reverse transcriptase inhibitor (NRTI), CCR5 antagonist, and integrase inhibitor classes of ARV agents do not have significant interactions with oral contraceptives. Drug interactions between ARV agents and HCs are described in Table 5. There are no data on safety or efficacy in altering hormonal dosages in an effort to circumvent these interactions, but a preparation containing a minimum of $30 \mu \mathrm{g}$ ethinyl estradiol (EE) is suggested [108]. Further study of the true clinical effect of pharmacokinetic drug interactions and the safety and efficacy of altering hormonal dosages in an effort to circumvent these interactions is warranted.

There is minimal information about drug interactions with use of alternative delivery methods for estrogenprogestin contraceptives (i.e., transdermal patch, intravaginal ring). However, a recent study suggests that these delivery methods may also be vulnerable to drug interactions and that different progestins (e.g., norethindrone versus norelgestr $\mathrm{min}$ ) may be affected differently in interaction with specific ARV agents [113]. Further study is required to better understand potential drug interactions and to determine their clinical significance.

There is no evidence showing a decrease in the contraceptive efficacy in depot medroxyprogesterone acetate (DMPA) when used with ARV therapy [114].

6.3. Hormonal Contraception and HIV Progression. Most studies suggest no association between the use of hormonal contraception and HIV disease progression [115-119]. In a longitudinal US cohort and a prospective cohort in Kenya, hormonal contraception was not associated with a change in viral load over time as compared to women who were not using hormonal contraception [120, 121]. One randomized controlled trial found an increased risk of declining CD4+ count or death among women using hormonal contraceptives as compared with women using a copper IUD; however, this study had significant loss to followup and method-switching among groups, weakening the strength of the analysis [119]. WHO convened an advisory group in February, 2012, to examine recent evidence related to hormonal contraception and HIV acquisition, progression, and transmission [115]. The group agreed that use of hormonal contraceptives should remain unrestricted if a strong clarification was added to the medical eligibility criteria for contraceptive use [109] that emphasized the need for a strong message about condom use and the need for couples to have access to a wide range of contraceptive methods. A clear recommendation was also made on the need for further research on this issue and a need to continue to closely review emerging evidence.

6.4. Hormonal Contraception and HIV Transmission or Acquisition. There are also conflicting data on the role of HC in HIV susceptibility or infectiousness. Two large prospective studies have shown a modestly increased risk of HIV acquisition associated with use of combined oral estrogen/progestin and/or DMPA [122-124]. A recent secondary analysis of data from a large prevention trial found an increased risk of HIV seroconversion (both transmission and acquisition) associated with hormonal contraception (primarily DMPA) among over 3700 serodiscordant African couples. Furthermore, women with HIV who transmitted to an HIV-uninfected male sex partner also had higher genital viral load, a potential mechanism for increased transmission [125]. However, there are also significant methodological 
TABLE 5: Drug interactions between antiretroviral agents and hormonal contraceptives.

\begin{tabular}{|c|c|c|}
\hline Antiretroviral (ARV) drug & Effect on drug levels & Dosing recommendation/clinical comment \\
\hline \multicolumn{3}{|c|}{ Nonnucleoside reverse transcriptase inhibitor (NNRTI) } \\
\hline \multirow{3}{*}{ Efavirenz (EFV) } & $\begin{array}{l}\text { Oral ethinyl estradiol/norgestimate No } \\
\text { effect on ethinyl estradiol } \\
\text { concentrations: } \downarrow \text { active metabolites of } \\
\text { norgestimate (levonorgestrel AUC } \\
\downarrow 83 \% \text {; norelgestromin AUC } \downarrow 64 \% \text { ) }\end{array}$ & $\begin{array}{l}\text { A reliable method of barrier contraception must be used in } \\
\text { addition to hormonal contraceptives. EFV had no effect on } \\
\text { ethinyl estradiol concentrations, but progestin levels } \\
\text { (norelgestromin and levonorgestrel) were markedly } \\
\text { decreased. No effect of ethinyl estradiol/norgestimate on } \\
\text { EFV plasma concentrations was observed. }\end{array}$ \\
\hline & Implant: $\downarrow$ etonogestrel & $\begin{array}{l}\text { A reliable method of barrier contraception must be used in } \\
\text { addition to hormonal contraceptives. The interaction } \\
\text { between etonogestrel and EFV has not been studied. } \\
\text { Decreased exposure of etonogestrel may be expected. There } \\
\text { have been postmarketing reports of contraceptive failure } \\
\text { with etonogestrel in EFV-exposed patients. }\end{array}$ \\
\hline & Levonorgestrel AUC $\downarrow 58 \%$ & $\begin{array}{l}\text { Effectiveness of emergency postcoital contraception may be } \\
\text { diminished }\end{array}$ \\
\hline Etravirine (ETR) & $\begin{array}{l}\text { Ethinyl estradiol AUC } \uparrow 22 \% \\
\text { Norethindrone: no significant effect }\end{array}$ & No dosage adjustment necessary \\
\hline Nevirapine (NVP) & $\begin{array}{l}\text { Ethinyl estradiol AUC } \downarrow 20 \% \\
\text { Norethindrone AUC } \downarrow 19 \%\end{array}$ & Use alternative or additional methods \\
\hline & DMPA: no significant change & No dosage adjustment needed \\
\hline \multicolumn{3}{|c|}{ Ritonavir-(RTV-) boosted protease inhibitor (PI) } \\
\hline Atazanavir/ritonavir (ATV/r) & $\begin{array}{l}\downarrow \text { Ethinyl estradiol } \\
\uparrow \text { Norgestimate }\end{array}$ & $\begin{array}{l}\text { Oral contraceptive should contain at least } 35 \mathrm{mcg} \text { of ethinyl } \\
\text { estradiol. Oral contraceptives containing progestins other } \\
\text { than norethindrone or norgestimate have not been studied }\end{array}$ \\
\hline Darunavir/ritonavir (DRV/r) & $\begin{array}{l}\text { Ethinyl estradiol AUC } \downarrow 44 \% \\
\text { Norethindrone AUC } \downarrow 14 \%\end{array}$ & Use alternative or additional method \\
\hline Fosamprenavir/ritonavir (FPV/r) & $\begin{array}{l}\text { Ethinyl estradiol AUC } \downarrow 37 \% \\
\text { Norethindrone AUC } \downarrow 34 \%\end{array}$ & Use alternative or additional method \\
\hline Lopinavir/ritonavir (LPV/r) & $\begin{array}{l}\text { Ethinyl estradiol AUC } \downarrow 42 \% \\
\text { Norethindrone AUC } \downarrow 17 \%\end{array}$ & Use alternative or additional method \\
\hline Saquinavir/ritonavir (SQV/r) & $\downarrow$ Ethinyl estradiol & Use alternative or additional method \\
\hline Tipranavir/ritonavir (TPV/r) & $\begin{array}{l}\text { Ethinyl estradiol AUC } \downarrow 48 \% \\
\text { Norethindrone: No significant change }\end{array}$ & Use alternative or additional method \\
\hline \multicolumn{3}{|c|}{ PI without RTV } \\
\hline Atazanavir (ATV) & $\begin{array}{l}\text { Ethinyl estradiol AUC } \uparrow 48 \% \\
\text { Norethindrone AUC } \uparrow 110 \%\end{array}$ & $\begin{array}{l}\text { Oral contraceptive should contain no more than } 30 \mathrm{mcg} \text { of } \\
\text { ethinyl estradiol or use alternative method. Oral } \\
\text { contraceptives containing less than } 25 \text { mcg of ethinyl } \\
\text { estradiol or progestins other than norethindrone or } \\
\text { norgestimate have not been studied }\end{array}$ \\
\hline Fosamprenavir (FPV) & $\begin{array}{l}\text { With APV: } \uparrow \text { ethinyl estradiol and } \uparrow \\
\text { norethindrone; } \downarrow \text { APV } 20 \%\end{array}$ & Use alternative method \\
\hline Indinavir (IDV) & $\begin{array}{l}\text { Ethinyl estradiol AUC } \uparrow 25 \% \\
\text { Norethindrone AUC } \uparrow 26 \%\end{array}$ & No dose adjustment \\
\hline Nelfinavir (NFV) & $\begin{array}{l}\text { Ethinyl estradiol AUC } \downarrow 47 \% \\
\text { Norethindrone AUC } \downarrow 18 \%\end{array}$ & Use alternative or additional method \\
\hline \multicolumn{3}{|c|}{ CCR5 antagonist } \\
\hline Maraviroc (MVC) & $\begin{array}{l}\text { No significant effect on ethinyl } \\
\text { estradiol or levonorgestrel }\end{array}$ & Safe to use in combination \\
\hline
\end{tabular}

Key to Abbreviations: AUC: area under the curve. DMPA: depot medroxyprogesterone acetate

Source: see [4].

issues with most studies, including potential selection bias confounding variables such as changes in HC use over time; presence of STIs - including herpes simplex virus 2 (HSV-2); and dependence on self-report regarding use of $\mathrm{HC}$, sexual behaviors, and condom use [126].
A WHO expert group reviewed all the available evidence and concluded that the data were not sufficient to warrant a change in the current guidance on the use of hormonal contraception for women at risk of HIV infection [115]. The WHO technical statement recommends no restrictions 
on the use of existing hormonal contraceptive methods for women at risk of HIV infection and that all women should have access to and use condoms and other measures to prevent and reduce the risk of HIV and other infections, particularly women on progestogen-only injectable contraception. The advisory group strongly recommended expansion of the current contraceptive method mix and further research on the relationship between hormonal contraception and HIV infection.

\section{Conclusion}

PCC, which includes contraceptive care, is an important component of primary health care services for all women living with HIV with the potential for childbearing. The goal of PCC is to ensure that every pregnancy is planned and well timed that pregnancy occurs in the context of optimal maternal health and that the risk of HIV transmission to an uninfected partner and to the infant is reduced to the fullest extent possible. To achieve this goal, health care providers can be proactive in addressing the reproductive intentions and contraceptive practices and needs of every HIV-infected woman. This is an ongoing process that begins when healthcare providers initiate nonjudgmental conversations with women living with HIV at every visit about pregnancy intentions, contraception needs, and sexual health.

\section{References}

[1] American College of Obstetricians and Gynecologists (ACOG), "ACOG Committee Opinion number 313, September 2005. The importance of preconception care in the continuum of women's health care," Obstetrics and Gynecology, vol. 106, no. 3, pp. 665-666.

[2] American College of Obstetricians Gynecologists (ACOG), "Gynecological care for women with human immunodefiiciency virus," Practice Bulletin, 2010, http://www.acog.org/ $\sim /$ media/Practice\%20Bulletins/Committee\%20on\%20Practice\%20Bulletins\%20-\%20Gynecology/Public/.pdf?dmc=1 \&ts $=20120216 \mathrm{~T} 2109570331$.

[3] K. Johnson, S. F. Posner, J. Biermann et al., "Recommendations to improve preconception health and health careUnited States. A report of the CDC/ATSDR Preconception Care Work Group and the Select Panel on Preconception Care," Morbidity and Mortality Weekly Reports. Recommendations and Reports, vol. 55, no. 6, pp. 1-23, 2006.

[4] Panel on Treatment of HIV-Infected Pregnant Women and Prevention of Perinatal Transmission, "Recommendations for Use of Antiretroviral Drugs in Pregnant HIV-1 Infected Women for Maternal Health and Interventions to Reduce Perinatal HIV Transmission in the United States," 2012, http://aidsinfo.nih.gov/guidelines/html/3/perinatalguidelines $/ 0 /$.

[5] A. Van Sighem, L. Gras, P. Reiss, K. Brinkman, and F. De Wolf, "Life expectancy of recently diagnosed asymptomatic HIV-infected patients approaches that of uninfected individuals," AIDS, vol. 24, no. 10, pp. 1527-1535, 2010.

[6] G. S. Birkhead, W. P. Pulver, B. L. Warren et al., "Progress in prevention of mother-to-child transmission of HIV in New York state: 1988-2008," Journal of Public Health Management and Practice, vol. 16, no. 6, pp. 481-491, 2010.
[7] Centers for Disease Control and Prevention (CDC), "HIV Surveillance Report," 2009, http://www.cdc.gov/hiv/ surveillance/resources/reports/2009report/.

[8] R. Hazra, G. K. Siberry, and L. M. Mofenson, "Growing up with HIV: children, adolescents, and young adults with perinatally acquired HIV infection," Annual Review of Medicine, vol. 61, pp. 169-185, 2010.

[9] A. Elgalib, A. Hegazi, A. Samarawickrama et al., "Pregnancy in HIV-infected teenagers in London," HIV Medicine, vol. 12, no. 2, pp. 118-123, 2011.

[10] M. Millery, S. Vazquez, V. Walther, N. Humphrey, J. Schlecht, and N. Van Devanter, "Pregnancies in perinatally HIVinfected young women and implications for care and service programs," Journal of the Association of Nurses in AIDS Care, vol. 23, no. 1, pp. 41-51, 2011.

[11] A. Sharma, J. G. Feldman, E. T. Golub et al., "Live birth patterns among human immunodeficiency virus-infected women before and after the availability of highly active antiretroviral therapy," American Journal of Obstetrics and Gynecology, vol. 196, no. 6, pp. e541-e546, 2007.

[12] L. S. Massad, G. Springer, L. Jacobson et al., "Pregnancy rates and predictors of conception, miscarriage and abortion in US women with HIV," AIDS, vol. 18, no. 2, pp. 281-286, 2004.

[13] J. L. Chen, K. A. Phillips, D. E. Kanouse, R. L. Collins, and A. Miu, "Fertility desires and intentions of HIV-positive men and women," Family Planning Perspectives, vol. 33, no. 4, pp. 144-165, 2001.

[14] S. Cliffe, C. L. Townsend, M. Cortina-Borja, and M.-L. Newell, "Fertility intentions of HIV-infected women in the United Kingdom," AIDS Care, vol. 23, no. 9, pp. 1093-1101, 2011.

[15] S. Finocchario-Kessler, M. D. Sweat, J. K. Dariotis et al., "Understanding high fertility desires and intentions among a sample of urban women living with HIV in the United States," AIDS and Behavior, vol. 14, no. 5, pp. 1106-1114, 2010.

[16] M. R. Loutfy, T. A. Hart, S. S. Mohammed et al., "Fertility desires and intentions of HIV-positive women of reproductive age in Ontario, Canada: a cross-sectional study," PloS ONE, vol. 4, no. 12, p. e7925, 2009.

[17] S. M. Craft, R. O. Delaney, D. T. Bautista, and J. M. Serovich, "Pregnancy decisions among women with HIV," AIDS and Behavior, vol. 11, no. 6, pp. 927-935, 2007.

[18] B. Nattabi, J. Li, S. C. Thompson, C. G. Orach, and J. Earnest, "A systematic review of factors influencing fertility desires and intentions among people living with HIV/AIDS: implications for policy and service delivery," AIDS and Behavior, vol. 13, no. 5, pp. 949-968, 2009.

[19] K. E. Squires, S. L. Hodder, J. Feinberg et al., "Health needs of HIV-infected women in the United States: insights from the women living positive survey," AIDS Patient Care and STDs, vol. 25, no. 5, pp. 279-285, 2011.

[20] S. Finocchario-Kessler, M. D. Sweat, J. K. Dariotis et al., "Childbearing motivations, pregnancy desires, and perceived partner response to a pregnancy among urban female youth: does HIV-infection status make a difference?" AIDS Care, vol. 24, no. 1, pp. 1-11, 2012.

[21] L. B. Finer and M. R. Zolna, "Unintended pregnancy in the United States: incidence and disparities, 2006," Contraception, vol. 84, no. 5, pp. 478-485, 2011.

[22] K. Kikuchi, N. Wakasugi, K. C. Poudel, K. Sakisaka, and M. Jimba, "High rate of unintended pregnancies after 
knowing of HIV infection among HIV positive women under antiretroviral treatment in Kigali, Rwanda," BioScience Trends, vol. 5, no. 6, pp. 255-263, 2011.

[23] L. J. Koenig, L. Espinoza, K. Hodge, and N. Ruffo, "Young, seropositive, and pregnant: epidemiologic and psychosocial perspectives on pregnant adolescents with human immunodeficiency virus infection," American Journal of Obstetrics and Gynecology, vol. 197, no. 3, pp. S123-S131, 2007.

[24] J. Kenny, B. Williams, K. Prime, P. Tookey, and C. Foster, "Pregnancy outcomes in adolescents in the UK and Ireland growing up with HIV," HIV Medicine, vol. 13, no. 5, pp. 304308, 2012.

[25] L. S. Massad, C. T. Evans, T. E. Wilson et al., "Contraceptive use among U.S. women with HIV," Journal of Women's Health, vol. 16, no. 5, pp. 657-666, 2007.

[26] S. Finocchario-Kessler, J. K. Dariotis, M. D. Sweat et al., "Do HIV-infected women want to discuss reproductive plans with providers, and are those conversations occurring?" AIDS Patient Care and STDs, vol. 24, no. 5, pp. 317-323, 2010.

[27] L. Panozzo, M. Battegay, A. Friedl et al., "High risk behaviour and fertility desires among heterosexual HIVpositive patients with a serodiscordant partner-two challenging issues," Swiss Medical Weekly, vol. 133, no. 7-8, pp. 124-127, 2003.

[28] M. A. Lampe, D. K. Smith, G. J. E. Anderson, A. E. Edwards, and S. R. Nesheim, "Achieving safe conception in HIVdiscordant couples: the potential role of oral preexposure prophylaxis (PrEP) in the United States," American Journal of Obstetrics and Gynecology, vol. 204, no. 6, pp. 488.e1-488.e8, 2011.

[29] A. Desgrées du Loû, P. Msellati, A. Yao et al., "Impaired fertility in HIV-1-infected pregnant women: a clinic-based survey in Abidjan, Côte d'Ivoire, 1997," AIDS, vol. 13, no. 4, pp. 517-521, 1999.

[30] J. R. Glynn, A. Buvé, M. Caraël et al., "Decreased fertility among HIV-1-infected women attending antenatal clinics in three African cities," Journal of Acquired Immune Deficiency Syndromes, vol. 25, no. 4, pp. 345-352, 2000.

[31] R. H. Gray, M. J. Wawer, D. Serwadda et al., "Populationbased study of fertility in women with HIV-1 infection in Uganda," The Lancet, vol. 351, no. 9096, pp. 98-103, 1998.

[32] L. M. Lee, P. M. Wortley, P. L. Fleming, L. J. Eldred, and R. H. Gray, "Duration of human immunodeficiency virus infection and likelihood of giving birth in a medicaid population in Maryland," American Journal of Epidemiology, vol. 151, no. 10, pp. 1020-1028, 2000.

[33] R. H. N. Nguyen, S. J. Gange, F. Wabwire-Mangen et al., "Reduced fertility among HIV-infected women associated with viral load in Rakai District, Uganda," International Journal of STD and AIDS, vol. 17, no. 12, pp. 842-846, 2006.

[34] S. Cu-Uvin, J. W. Hogan, D. Warren et al., "Prevalence of lower genital tract infections among human immunodeficiency virus (HIV)-seropositive and high-risk HIVseronegative women," Clinical Infectious Diseases, vol. 29, no. 5, pp. 1145-1150, 1999.

[35] S. Cu-Uvin, H. Ko, D. J. Jamieson et al., "Prevalence, incidence, and persistence or recurrence of trichomoniasis among human immunodeficiency virus (HIV)-positive women and among HIV-negative women at high risk for HIV infection," Clinical Infectious Diseases, vol. 34, no. 10, pp. 1406-1411, 2002.

[36] C. R. Cohen, "Effect of human immunodeficiency virus type 1 infection upon acute salpingitis: a laparoscopic study,"
Journal of Infectious Diseases, vol. 178, no. 5, pp. 1352-1358, 1998.

[37] K. L. Irwin, A. C. Moorman, M. J. O’Sullivan et al., "Influence of human immunodeficiency virus infection on pelvic inflammatory disease," Obstetrics and Gynecology, vol. 95, no. 4, pp. 525-534, 2000.

[38] O. Coll, M. Lopez, R. Vidal et al., "Fertility assessment in non-infertile HIV-infected women and their partners," Reproductive BioMedicine Online, vol. 14, no. 4, article 2645, pp. 488-494, 2007.

[39] H. E. Cejtin, A. Kalinowski, P. Bacchetti et al., "Effects of human immunodeficiency virus on protracted amenorrhea and ovarian dysfunction," Obstetrics and Gynecology, vol. 108, no. 6, pp. 1423-1431, 2006.

[40] O. C. Ezechi, A. Jogo, C. Gab-Okafor et al., "Effect of HIV-1 infection and increasing immunosuppression on menstrual function," Journal of Obstetrics and Gynaecology Research, vol. 36, no. 5, pp. 1053-1058, 2010.

[41] S. D. Harlow, P. Schuman, M. Cohen et al., "Effect of HIV infection on menstrual cycle length," Journal of Acquired Immune Deficiency Syndromes, vol. 24, no. 1, pp. 68-75, 2000.

[42] L. S. Massad, C. T. Evans, H. Minkoff et al., "Effects of HIV infection and its treatment on self-reported menstrual abnormalities in women," Journal of Women's Health, vol. 15, no. 5, pp. 591-598, 2006.

[43] F. E. Makumbi, G. Nakigozi, S. J. Reynolds et al., "Associations between HIV antiretroviral therapy and the prevalence and incidence of pregnancy in Rakai, Uganda," AIDS Research and Treatment, vol. 2011, Article ID 519492, 10 pages, 2011.

[44] L. Myer, R. J. Carter, M. Katyal, P. Toro, W. M. El-Sadr, and E. J. Abrams, "Impact of antiretroviral therapy on incidence of pregnancy among HIV-infected women in Sub-Saharan Africa: a cohort study," PLoS Medicine, vol. 7, no. 2, Article ID e1000229, 2010.

[45] H. Tweya, C. Feldacker, E. Breeze et al., "Incidence of pregnancy among women accessing antiretroviral therapy in Urban Malawi: a retrospective cohort study," AIDS and Behavior, http://www.springerlink.com.libproxy2.umdnj .edu/content/n82815417n281167/.

[46] M. Sandelowski, C. Lambe, and J. Barroso, "Stigma in HIVpositive women," Journal of Nursing Scholarship, vol. 36, no. 2, pp. 122-128, 2004.

[47] L. B. Sanders, "Sexual behaviors and practices of women living with HIV in relation to pregnancy," Journal of the Association of Nurses in AIDS Care, vol. 20, no. 1, pp. 62-68, 2009.

[48] A. C. Wagner, T. A. Hart, S. Mohammed, E. Ivanova, J. Wong, and M. R. Loutfy, "Correlates of HIV stigma in HIV-positive women," Archives of Women's Mental Health, vol. 13, no. 3, pp. 207-214, 2010.

[49] S. Richardson, "Guide for HIV/AIDS clinical care of HIVinfected women through the life cycle," Guide for HIV/AIDS Clinical Care, HRA HIV/AIDS Bureau, 2011.

[50] S. Kathleen, J. Voss, and D. Li, "Female disclosure of HIVpositive serostatus to sex partners: a two-city study," Women and Health, vol. 50, no. 6, pp. 506-526, 2010.

[51] T. E. Wilson, J. Feldman, M. Y. Vega et al., "Acquisition of new sexual partners among women with HIV infection: patterns of disclosure and sexual behavior within new partnerships," AIDS Education and Prevention, vol. 19, no. 2, pp. 151-159, 2007.

[52] Panel on Antiretroviral Guidelines for Adults and Adolescents, "Guidelines for the use of antiretroviral 
agents in HIV-1-infected adults and adolescents," 2012, http://www.aidsinfo.nih.gov/ContentFiles/AdultandAdolescentGL.pdf.

[53] C. Jasseron, L. Mandelbrot, C. Dollfus et al., "Non-disclosure of a pregnant Woman's HIV status to her partner is associated with non-optimal prevention of mother-to-child transmission," AIDS and Behavior, http://www.springerlink. com.libproxy2.umdnj.edu/content/619212838376p285/fulltext.pdf.

[54] S. Wilson, "HIV and pregnancy: challenges in practice," Practising Midwife, vol. 14, no. 3, pp. 16-18, 2011.

[55] K. M. Forbes, N. Lomax, L. Cunningham et al., "Partner notification in pregnant women with HIV: findings from three inner-city clinics," HIV Medicine, vol. 9, no. 6, pp. 433$435,2008$.

[56] J. D. Makin, B. W. C. Forsyth, M. J. Visser, K. J. Sikkema, S. Neufeld, and B. Jeffery, "Factors affecting disclosure in South African HIV-positive pregnant women," AIDS Patient Care and STDs, vol. 22, no. 11, pp. 907-916, 2008.

[57] T. T. Brown, S. R. Cole, X. Li et al., "Antiretroviral therapy and the prevalence and incidence of diabetes mellitus in the multicenter AIDS cohort study," Archives of Internal Medicine, vol. 165, no. 10, pp. 1179-1184, 2005.

[58] P. C. Tien, M. F. Schneider, S. R. Cole et al., "Antiretroviral therapy exposure and incidence of diabetes mellitus in the Women's Interagency HIV Study," AIDS, vol. 21, no. 13, pp. 1739-1745, 2007.

[59] C. L. Townsend, M. Cortina-Borja, C. S. Peckham, A. De Ruiter, H. Lyall, and P. A. Tookey, "Low rates of motherto-child transmission of HIV following effective pregnancy interventions in the United Kingdom and Ireland, 20002006," AIDS, vol. 22, no. 8, pp. 973-981, 2008.

[60] R. Tubiana, J. Le Chenadec, C. Rouzioux et al., "Factors associated with mother-to-child transmission of HIV-1 despite a maternal viral load $<500$ Copies/ $\mathrm{ml}$ at Delivery: a casecontrol study nested in the french perinatal cohort (EPFANRS COl)," Clinical Infectious Diseases, vol. 50, no. 4, pp. 585-596, 2010.

[61] A. P. Kourtis, C. H. Schmid, D. J. Jamieson, and J. Lau, "Use of antiretroviral therapy in pregnant HIV-infected women and the risk of premature delivery: a meta-analysis," AIDS, vol. 21, no. 5, pp. 607-615, 2007.

[62] C. Rudin, A. Spaenhauer, O. Keiser et al., "Antiretroviral therapy during pregnancy and premature birth: analysis of Swiss data," HIV Medicine, vol. 12, no. 4, pp. 228-235, 2011.

[63] N. Ford, L. Mofenson, K. Kranzer et al., "Safety of efavirenz in first-trimester of pregnancy: a systematic review and metaanalysis of outcomes from observational cohorts," AIDS, vol. 24, no. 10, pp. 1461-1470, 2010.

[64] L. F. Johnson and D. A. Lewis, "The effect of genital tract infections on HIV-1 shedding in the genital tract: a systematic review and meta-analysis," Sexually Transmitted Diseases, vol. 35, no. 11, pp. 946-959, 2008.

[65] F. A. Plummer, "Heterosexual transmission of human immunodeficiency virus type 1 (HIV): interactions of conventional sexually transmitted diseases, hormonal contraception and HIV-1," AIDS Research and Human Retroviruses, vol. 14, no. 1, pp. S5-S10, 1998.

[66] L. J. M. Bollen, S. J. Whitehead, P. A. Mock et al., "Maternal herpes simplex virus type 2 coinfection increases the risk of perinatal HIV transmission: possibility to further decrease transmission?” AIDS, vol. 22, no. 10, pp. 1169-1176, 2008.

[67] F. Z. Gumbo, K. Duri, G. Q. Kandawasvika et al., "Risk factors of HIV vertical transmission in a cohort of women under a
PMTCT program at three peri-urban clinics in a resourcepoor setting," Journal of Perinatology, vol. 30, no. 11, pp. 717723, 2010.

[68] M. J. Lee, R. J. Hallmark, L. M. Frenkel, and G. Del Priore, "Maternal syphilis and vertical perinatal transmission of human immunodeficiency virus type-1 infection," International Journal of Gynecology and Obstetrics, vol. 63, no. 3, pp. 247-252, 1998.

[69] A. R. Lifson and H. A. Lando, "Smoking and HIV: prevalence, health risks, and cessation strategies," Current HIV/AIDS Reports, 2012.

[70] B. King, S. Dube, R. Kaufmann, L. Shaw, and T. Pechacek, "Vital signs: current cigarette smoking among adults aged $\geq 18$ Years-United States, 2005-2010," Morbidity and Mortality Weekly Report, vol. 60, no. 35, pp. 1207-1212, 2011.

[71] F. H. Galvan, E. G. Bing, J. A. Fleishman et al., "The prevalence of alcohol consumption and heavy drinking among people with HIV in the United States: results from the HIV cost and services utilization study," Journal of Studies on Alcohol, vol. 63, no. 2, pp. 179-186, 2002.

[72] S. C. Kalichman, C. M. Amaral, D. White et al., "Prevalence and clinical implications of interactive toxicity beliefs regarding mixing alcohol and antiretroviral therapies among people living with HIV/AIDS," AIDS Patient Care and STDs, vol. 23, no. 6, pp. 449-454, 2009.

[73] J. M. Holmes, K. R. Gerhardstein, and P. T. Griffin, "Brief screening for alcohol use disorders in HIV primary care," HIV Clinician, vol. 23, no. 4, pp. 8-13, 2011.

[74] S. C. Kalichman, C. M. Amaral, D. White et al., "Alcohol and adherence to antiretroviral medications: interactive toxicity beliefs among people living with HIV," Journal of the Association of Nurses in AIDS Care. In press.

[75] Centers for Disease Control and Prevention, "HIV Surveillance-epidemiology of HIV Infection," 2010, http://www.cdc.gov/hiv/topics/surveillance/resources/slides/ general/index.htm.

[76] H. E. Hutton, M. E. McCaul, G. Chander et al., "Alcohol use, anal sex, and other risky sexual behaviors among HIV-infected women and men," AIDS and Behavior, http://www.springerlink.com.libproxy2.umdnj.edu/content/ 5547552wnjp22833.

[77] J. M. Sales, J. L. Brown, A. T. Vissman, and R. J. DiClemente, "The association between alcohol use and sexual risk behaviors among African American women across three developmental periods: a review," Current Drug Abuse Reviews, vol. 5, no. 2, pp. 117-128, 2012.

[78] P. Seth, G. M. Wingood, R. J. DiClemente, and L. S. Robinson, "Alcohol use as a marker for risky sexual behaviors and biologically confirmed sexually transmitted infections among young adult African-American women," Women's Health Issues, vol. 21, no. 2, pp. 130-135, 2011.

[79] S. K. Whitmore, A. W. Taylor, L. Espinoza, R. L. Shouse, M. A. Lampe, and S. Nesheim, "Correlates of mother-to-child transmission of HIV in the United States and Puerto Rico," Pediatrics, vol. 129, no. 1, pp. e74-e81, 2012.

[80] Practice Committee of American Society for Reproductive Medicine, "Smoking and infertility," Fertility and Sterility, vol. 90, no. 5, supplement, pp. S254-S259, 2008.

[81] B. G. Armstrong, A. D. McDonald, and M. Sloan, "Cigarette, alcohol, and coffee consumption and spontaneous abortion," American Journal of Public Health, vol. 82, no. 1, pp. 85-87, 1992. 
[82] J. A. Martin, H. C. Kung, T. J. Mathews et al., "Annual summary of vital statistics: 2006," Pediatrics, vol. 121, no. 4, pp. 788-801, 2008.

[83] M. H. Aliyu, H. Weldeselasse, E. M. August, Keith L. G., Salihu H. M., "Cigarette smoking and fetal morbidity outcomes in a large cohort of HIV-infected mothers," Nicotine \& Tobacco Research, http://ntr.oxfordjournals. org/content/early/2012/05/09/ntr.nts105.abstract.

[84] B. J. Dattel, "Substance abuse in pregnancy," Seminars in Perinatology, vol. 14, no. 2, pp. 179-187, 1990.

[85] K. Gouin, K. Murphy, and P. S. Shah, "Effects of cocaine use during pregnancy on low birthweight and preterm birth: systematic review and metaanalyses," American Journal of Obstetrics and Gynecology, vol. 204, no. 4, pp. 340.e1340.e12, 2011.

[86] L. Goldschmidt, G. A. Richardson, D. S. Stoffer, D. Geva, and N. L. Day, "Prenatal alcohol exposure and academic achievement at age six: a nonlinear fit," Alcoholism, vol. 20, no. 4, pp. 763-770, 1996.

[87] N. J. Bodsworth, D. A. Cooper, and B. Donovan, "The influence of human immunodeficiency virus type 1 infection on the development of the hepatitis B virus carrier state," Journal of Infectious Diseases, vol. 163, no. 5, pp. 1138-1140, 1991.

[88] H. H. Thein, Q. Yi, G. J. Dore, and M. D. Krahn, "Natural history of hepatitis $\mathrm{C}$ virus infection in HIV-infected individuals and the impact of HIV in the era of highly active antiretroviral therapy: a meta-analysis," AIDS, vol. 22, no. 15, pp. 1979-1991, 2008.

[89] C. L. Thio, E. C. Seaberg, R. Skolasky Jr. et al., "HIV-1, hepatitis B virus, and risk of liver-related mortality in the Multicenter Cohort Study (MACS)," The Lancet, vol. 360, no. 9349, pp. 1921-1926, 2002.

[90] J. Y. Phelps, "Restricting access of human immunodeficiency virus (HIV)-seropositive patients to infertility services: a legal analysis of the rights of reproductive endocrinologists and of HIV-seropositive patients," Fertility and Sterility, vol. 88, no. 6, pp. 1483-1490, 2007.

[91] P. Barreiro, J. A. Castilla, P. Labarga, and V. Soriano, "Is natural conception a valid option for HIV-serodiscordant couples?" Human Reproduction, vol. 22, no. 9, pp. 2353-2358, 2007.

[92] S. Attia, M. Egger, M. Müller, M. Zwahlen, and N. Low, "Sexual transmission of HIV according to viral load and antiretroviral therapy: systematic review and meta-analysis," AIDS, vol. 23, no. 11, pp. 1397-1404, 2009.

[93] M. S. Cohen, Y. Q. Chen, M. McCauley et al., "Prevention of HIV-1 infection with early antiretroviral therapy," The New England Journal of Medicine, vol. 365, no. 6, pp. 493-505, 2011.

[94] S. Cu-Uvin, A. K. DeLong, K. K. Venkatesh et al., "Genital tract HIV-1 RNA shedding among women with below detectable plasma viral load," AIDS, vol. 24 , no. 16, pp. 2489 2497, 2010.

[95] A. G. Marcelin, R. Tubiana, S. Lambert-Niclot et al., "Detection of HIV-1 RNA in seminal plasma samples from treated patients with undetectable HIV-1 RNA in blood plasma," AIDS, vol. 22, no. 13, pp. 1677-1679, 2008.

[96] P. M. Sheth, C. Kovacs, K. S. Kemal et al., "Persistent HIV RNA shedding in semen despite effective antiretroviral therapy," AIDS, vol. 23, no. 15, pp. 2050-2054, 2009.
[97] S. Taylor and S. Davies, "Antiretroviral drug concentrations in the male and female genital tract: implications for the sexual transmission of HIV," Current Opinion in HIV and AIDS, vol. 5, no. 4, pp. 335-343, 2010.

[98] S. Kehl, M. Weigel, D. Müller, M. Gentili, A. Hornemann, and M. Sütterlin, "HIV-infection and modern antiretroviral therapy impair sperm quality," Archives of Gynecology and Obstetrics, vol. 284, no. 1, pp. 229-233, 2011.

[99] J. D. M. Nicopoullos, P. A. Almeida, J. W. A. Ramsay, and C. Gilling-Smith, "The effect of human immunodeficiency virus on sperm parameters and the outcome of intrauterine insemination following sperm washing," Human Reproduction, vol. 19, no. 10, pp. 2289-2297, 2004.

[100] E. Van Leeuwen, F. W. Wit, S. Repping et al., "Effects of antiretroviral therapy on semen quality," AIDS, vol. 22, no. 5, pp. 637-642, 2008.

[101] Q. A. Karim, S. S. A. Karim, J. A. Frohlich et al., "Effectiveness and safety of tenofovir gel, an antiretroviral microbicide, for the prevention of HIV infection in women," Science, vol. 329, no. 5996, pp. 1168-1174, 2010.

[102] R. M. Grant, J. R. Lama, P. L. Anderson et al., "Preexposure chemoprophylaxis for HIV prevention in men who have sex with men," The New England Journal of Medicine, vol. 363, no. 27, pp. 2587-2599, 2010.

[103] N. L. Michael, "Oral preexposure prophylaxis for HIVanother arrow in the quiver," The New England Journal of Medicine, vol. 363, no. 27, pp. 2663-2665, 2010.

[104] C. Celum and J. M. Baeten, "Tenofovir-based pre-exposure prophylaxis for HIV prevention: evolving evidence," Current Opinion in Infectious Diseases, vol. 25, no. 1, pp. 51-57, 2012.

[105] Committee on Ethics of the American College of Obstetricians and Gynecologists (ACOG), "Human immunodeficiency virus: ethical guidelines for obstetricians and gynecologists. Number 389,” 2007, http:// www.acog.org/Resources_And_Publications/Committee_ Opinions/Committee_on_Ethics/Human_Immunodeficiency _Virus.

[106] L. Bujan, L. Hollander, M. Coudert et al., "Safety and efficacy of sperm washing in HIV-1-serodiscordant couples where the male is infected: results from the European CREAThE network," AIDS, vol. 21, no. 14, pp. 1909-1914, 2007.

[107] E. S. Daar and J. F. Daar, "Human immunodeficiency virus and fertility care: embarking on a path of knowledge and access," Fertility and Sterility, vol. 85, no. 2, pp. 298-301, 2006.

[108] Centers for Disease Control and Prevention (CDC), "U. S. medical eligibility criteria for contraceptive use, 2010," Morbidity and Mortality Weekly Reports. Recommendations and Reports, vol. 59, no. 4, pp. 1-86, 2010.

[109] World Health Organization, Medical Eligibility Criteria for Contraceptive Use, WHO, 4th edition, 2009.

[110] B. A. Richardson, C. S. Morrison, C. Sekadde-Kigondu et al., "Effect of intrauterine device use on cervical shedding of HIV-1 DNA," AIDS, vol. 13, no. 15, pp. 2091-2097, 1999.

[111] E. M. Stringer, C. Kaseba, J. Levy et al., "A randomized trial of the intrauterine contraceptive device vs hormonal contraception in women who are infected with the human immunodeficiency virus," American Journal of Obstetrics and Gynecology, vol. 197, no. 2, pp. 144.e1-144.e8, 2007.

[112] S. Y. El-Ibiary and J. M. Cocohoba, "Effects of HIV antiretrovirals on the pharmacokinetics of hormonal contraceptives," European Journal of Contraception and Reproductive Health Care, vol. 13, no. 2, pp. 123-132, 2008. 
[113] M. A. Vogler, K. Patterson, L. Kamemoto et al., "Contraceptive efficacy of oral and transdermal hormones when co-administered with protease inhibitors in HIV-1-infected women: pharmacokinetic results of ACTG trial A5188," Journal of Acquired Immune Deficiency Syndromes, vol. 55, no. 4, pp. 473-482, 2010.

[114] S. E. Cohn, J. G. Park, D. H. Watts et al., "Depomedroxyprogesterone in women on antiretroviral therapy: effective contraception and lack of clinically significant interactions," Clinical Pharmacology and Therapeutics, vol. 81, no. 2, pp. 222-227, 2007.

[115] World Health Organization, "Hormonal contraception and HIV: technical Statement," 2012, http:// whqlibdoc.who.int/hq/2012/WHO_RHR_12.08_eng.pdf.

[116] C. S. Morrison, P. L. Chen, I. Nankya et al., "Hormonal contraceptive use and HIV disease progression among women in Uganda and Zimbabwe," Journal of Acquired Immune Deficiency Syndromes, vol. 57, no. 2, pp. 157-164, 2011.

[117] C. B. Polis, M. J. Wawer, N. Kiwanuka et al., "Effect of hormonal contraceptive use on HIV progression in female HIV seroconverters in Rakai, Uganda," AIDS, vol. 24, no. 12, pp. 1937-1944, 2010.

[118] E. M. Stringer, M. Giganti, R. J. Carter, W. El-Sadr, E. J. Abrams, and J. S. A. Stringer, "Hormonal contraception and HIV disease progression: a multicountry cohort analysis of the MTCT-Plus Initiative," AIDS, vol. 23, supplement 1, pp. S69-S77, 2009.

[119] E. M. Stringer, J. Levy, M. Sinkala et al., "HIV disease progression by hormonal contraceptive method: secondary analysis of a randomized trial," AIDS, vol. 23, no. 11, pp. 1377-1382, 2009.

[120] H. E. Cejtin, L. Jacobson, G. Springer et al., "Effect of hormonal contraceptive use on plasma HIV-1-RNA levels among HIV-infected women," AIDS, vol. 17, no. 11, pp. 1702-1704, 2003.

[121] B. A. Richardson, P. A. Otieno, D. Mbori-Ngacha, J. Overbaugh, C. Farquhar, and G. C. John-Stewart, "Hormonal contraception and HIV-1 disease progression among postpartum Kenyan women," AIDS, vol. 21, no. 6, pp. 749-753, 2007.

[122] J. M. Baeten, S. Benki, V. Chohan et al., "Hormonal contraceptive use, herpes simplex virus infection, and risk of HIV-1 acquisition among Kenyan women," AIDS, vol. 21, no. 13, pp. 1771-1777, 2007.

[123] L. Lavreys, V. Chohan, J. Overbaugh et al., "Hormonal contraception and risk of cervical infections among HIV-1seropositive Kenyan women," AIDS, vol. 18, no. 16, pp. 21792184, 2004.

[124] C. S. Morrison, P. L. Chen, C. Kwok et al., "Hormonal contraception and HIV acquisition: reanalysis using marginal structural modeling," AIDS, vol. 24, no. 11, pp. 1778-1781, 2010.

[125] R. Heffron, D. Donnell, H. Rees et al., "Use of hormonal contraceptives and risk of HIV-1 transmission: a prospective cohort study," The Lancet Infectious Diseases, vol. 12, no. 1, pp. 19-26, 2012.

[126] C. A. Blish and J. M. Baeten, "Hormonal Contraception and HIV-1 Transmission," American Journal of Reproductive Immunology, vol. 65, no. 3, pp. 302-307, 2011. 


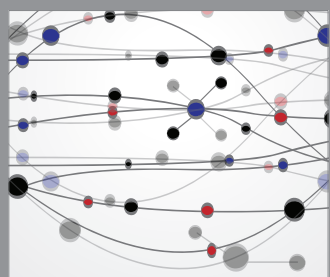

The Scientific World Journal
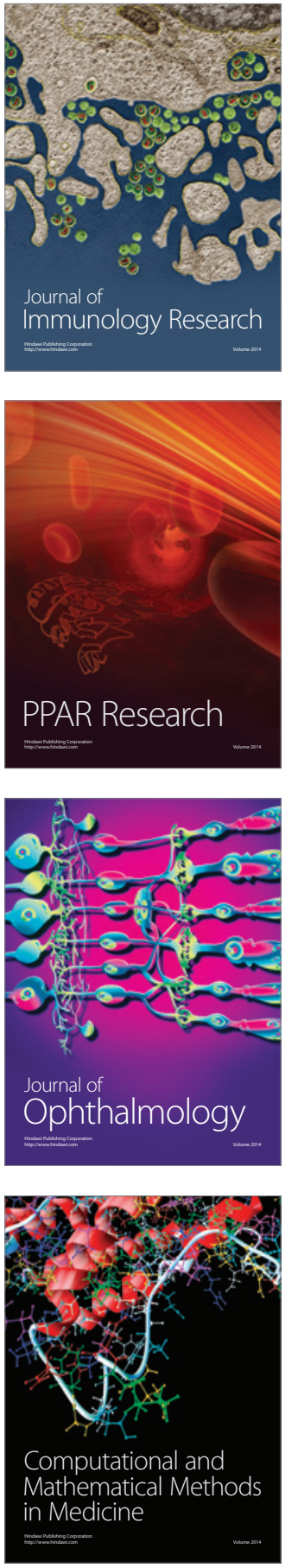

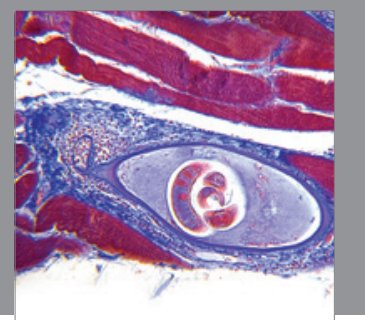

Gastroenterology

Research and Practice
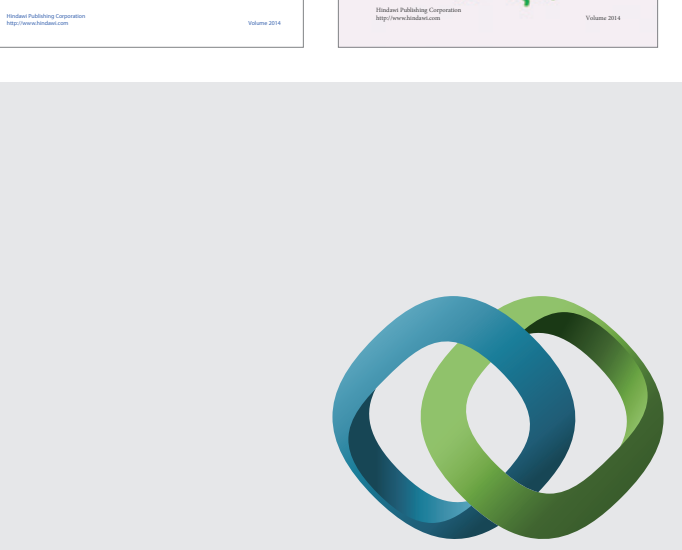

\section{Hindawi}

Submit your manuscripts at

http://www.hindawi.com
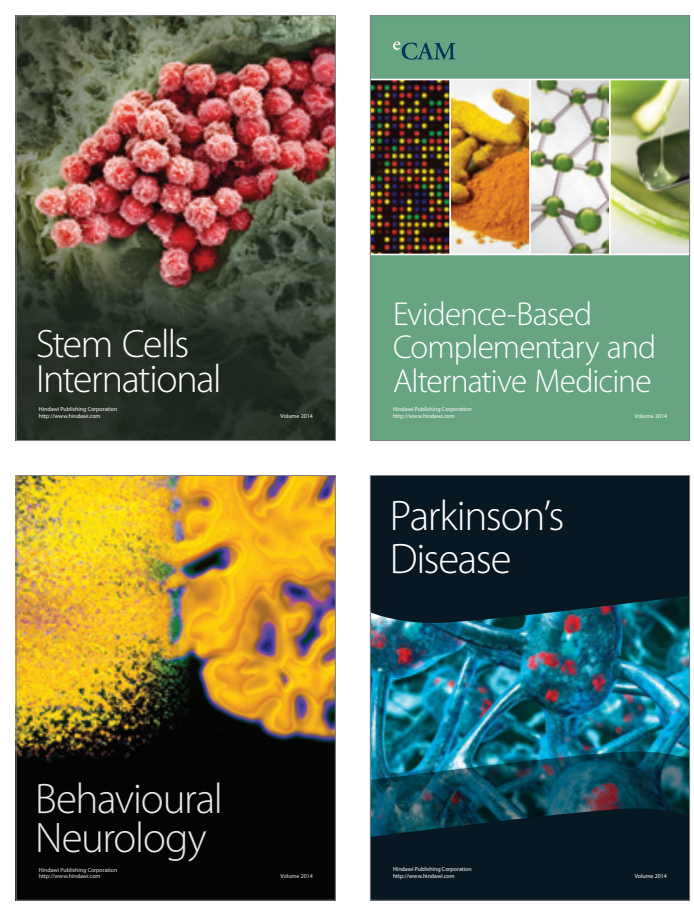

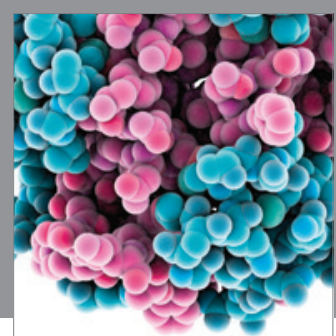

Journal of
Diabetes Research

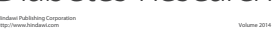

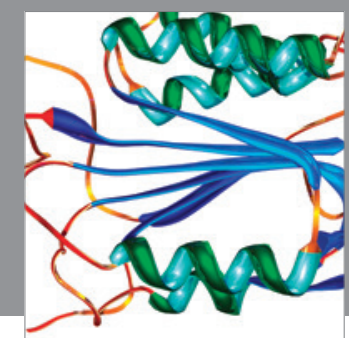

Disease Markers
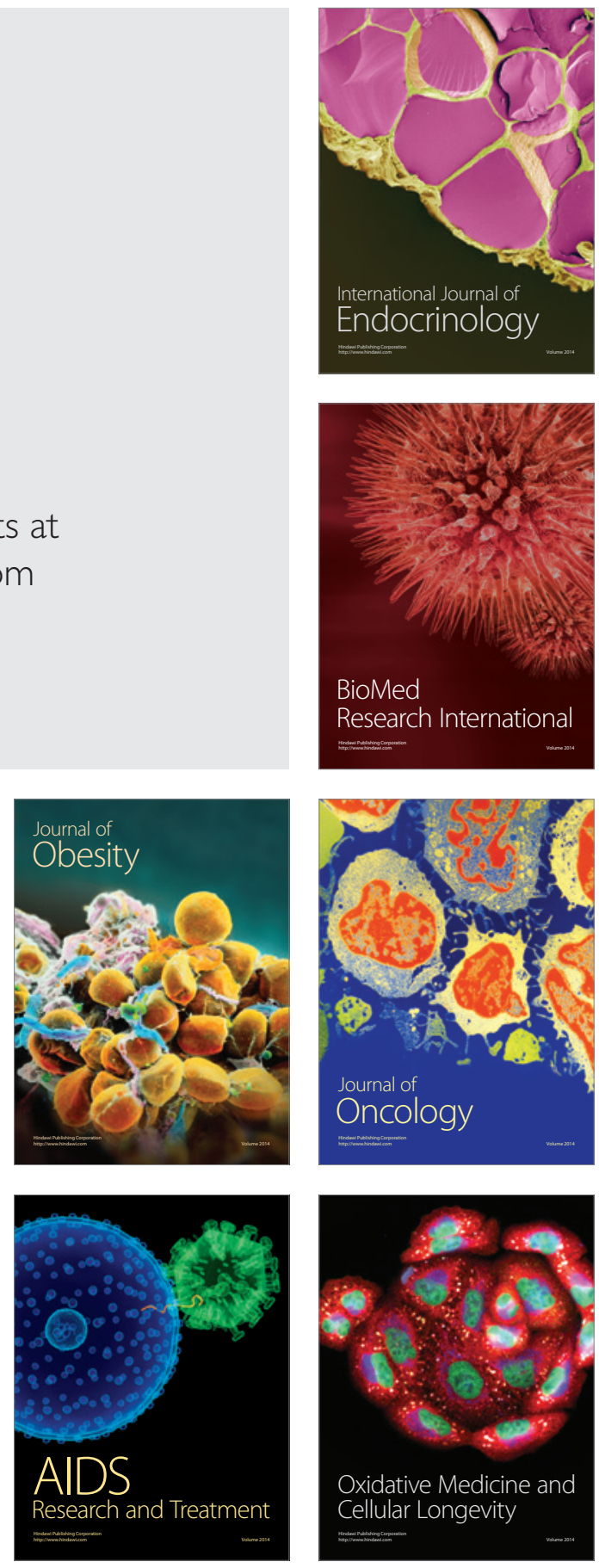